\title{
Bêta-galactosidases et phospho-bêta-galactosidases de Streptococcus thermophilus
}

\author{
par \\ D. HEMME, Michèle NARDI et D. JETTE*
}

\section{INTRODUCTION}

Depuis la mise en évidence par Citti et al. [4], en 1965, d'une $\beta$-galactosidase (B-gal) chez Streptococcus lactis 7962, une dizaine d'autres études ont été consacrées au métabolisme glucidique de divers streptocoques (voir la revue de Lawrence et Thomas [15]), et ont permis de mettre en évidence une phospho- $\beta$-galactosidase (P- $\beta$-gal) chez la très grande majorité des souches étudiées.

Par contre l'étude du métabolisme de $S$. thermophilus n'a été entreprise que récemment (voir la revue d'Accolas et al. [3]). Wierzbicki et Kosikowski [37] furent les premiers, en 1973, à signaler l'existence d'une $\beta$-gal chez cette espèce. On a récemment confirmé l'existence d'une $\beta$-gal et étudié certaines propriétés de l'enzyme chez une souche (Rao et Dutta [27, 28]), étudié l'influence de l'hydrolyse du lactose, variable selon les souches (Hemme, Wahl et Nardi [12]), ainsi que l'adaptation de 31 souches à la source carbonée (Somkuti et Steinberg [31]).

Le présent travail avait deux objectifs. Le premier était de caractériser les $\beta$-gal et P- $\beta$-gal de $S$. thermophilus et de comparer leurs caractéristiques à la $\beta$-gal de S. lactis 7962 et aux P- $\beta$-gal des streptocoques lactiques mésophiles. Le second était de comparer un nombre suffisamment grand de souches, afin d'évaluer les variations au sein de l'espèce et de détecter éventuellement des souches atypiques. Ce travail complète les travaux récents que nous avons effectués intéressant l'équipement enzymatique de $S$. thermophilus (Hemme et al. [12]), la comparaison électrophorétique des protéines et de certaines enzymes (Hemme et Nardi [9]), l'effet de l'hydrolyse du lactose sur la production d'acide (Hemme, Vassal, Foyen et Auclair

* Institut National de la Recherche Agronomique, C.N.R.Z., Laboratoire de microbiologie laitière et de génie alimentaire - 78350 Jouy-en-Josas (France). 
[11]) et la stimulation de la production d'acide de $S$. thermophilus par des extraits de lactobacilles (Hemme, Schmal et Auclair [10]).

\section{MATERIELS ET METHODES}

\section{Souches}

Les souches de $S$. thermophilus étudiées appartenaient à la collection du Centre National de Recherches Zootechniques (C.N.R.Z.) de Jouy-en-Josas. L'origine des souches et le mode de culture sur milieu M 17 [32] ont été décrits dans un précédent travail [9]. La température optimale de croissance a été déterminée en ensemençant les cultures avec un inoculum ( $4 \mathrm{p}$. 100) provenant d'une préculture sur milieu M17. Le milieu ensemencé était réparti en tubes stériles bouchés et ceux-ci étaient incubés à $37,41,45$ et $49^{\circ} \mathrm{C}$. Des tubes étaient prélevés régulièrement et le $\mathrm{pH}$ était mesuré. Les courbes de production d'acide correspondantes étaient établies en utilisant une échelle de correspondance entre le $\mathrm{pH}$ et la quantité d'acide produite dans le milieu. Cette échelle était établie en mesurant le $\mathrm{pH}$ du milieu M 17 obtenu après addition de volumes connus de lactate de $\mathrm{Na}$ à 30 p. 100 (Touzart et Matignon).

\section{Préparation des extraits bruts solubles}

Elle a été effectuée conformément à celle décrite par Hemme et Nardi [9]. Après broyage mécanique des cellules et centrifugation à $13000 \mathrm{~g}$, on obtenait des surnageants qui constituaient les extraits bruts solubles.

\section{Dosage des protéines et des enzymes}

Les protéines étaient dosées par la méthode de Lowry et al. [in 12]. Les activités spécifiques étaient rapportées aux concentrations en protéines ainsi déterminées. Les activités ont été déterminées comme suit :

$\beta$-gal : l'activité $\beta$-gal était mesurée dans du tampon phosphate de $\mathrm{Na}(50 \mathrm{mM})$ contenant le substrat ONPG (ortho-nitrophényl- $\beta-D$ galactoside) à une concentration saturante pour les enzymes de toutes les souches $(5 \mathrm{mM})$. Dans un certain nombre de cas on a établi la cinétique de la réaction en enregistrant la variation de D.O. à $420 \mathrm{~nm}$ pendant 2 min (spectrophotomètre Beckman UV 25). A 0,65 $\mathrm{ml}$ du mélange réactionnel équilibré à $30^{\circ} \mathrm{C}$ dans la cuve de mesure (cuve plastique semi-micro), on ajoutait $0,05 \mathrm{ml}$ d'extrait brut plus ou moins dilué dans le même tampon phosphate. La dilution de l'extrait variait de $1 / 21$ pour les extraits étudiés aussitôt après cassage, à $1 / 1$ pour les extraits congelés et conservés plus d'une année à $-20^{\circ} \mathrm{C}$. Les variations de D.O. utilisées allaient de 0,020 à 0,500 unité de D.O./ 
$2 \mathrm{~min}$, les tracés obtenus étant toujours des droites, confondues avec la pente à l'origine. Pour certains essais $(\mathrm{pH}$, optimum de température), les mesures par cette méthode cinétique n'étaient pas utilisables. Dans ces cas la réaction était effectuée dans un tube pendant des temps variant de 5 à $15 \mathrm{~min}$, après quoi on ajoutait $0,35 \mathrm{ml}$ de carbonate de $\mathrm{K}(1 \mathrm{M})$ pour arrêter la réaction. L'unité d'activité pour la $\beta$-gal était calculée en se reportant à celle d'une $\beta$-gal purifiée d'Escherichia coli (Boehringer Mannheim France), mesurée dans nos conditions expérimentales (1 unité de D.O./2 $\mathrm{min}=$ $2,14 \mathrm{U} / \mathrm{ml}$ ). Lorsque la réaction était arrêtée par le carbonate, l'unité était définie comme la quantité d'enzyme libérant 1 micromole d'ONP/min (1 unité de D.O./min = 1,18 U/ml). L'hydrolyse du lactose par les $\beta$-gal était mesurée par dosage du galactose et du glucose libérés, en utilisant des mélanges réactionnels du commerce (galactose UV et Gluco-Quant, Boeringer Mannheim France). En prenant comme référence la $\beta$-gal d'E. coli, une variation de D.O. à $340 \mathrm{~nm} / 2 \mathrm{~min}$ égale à l'unité correspondait à $21,25 \mathrm{U} / \mathrm{ml}$.

P-ß-gal : l'activité P- $\beta$-gal était mesurée dans les mêmes conditions que l'activité $\beta$-gal, mais avec de I'ONPG-6-phosphate comme substrat (Sigma) au lieu de l'ONPG.

\section{Propriétés des enzymes}

Inactivation thermique : $1 \mathrm{ml}$ d'extrait était chauffé dans un tube de verre pendant des temps variables aux températures désirées. Après refroidissement immédiat dans la glace fondante, les activités résiduelles étaient mesurées.

Stabilité à $4^{\circ} \mathrm{C}$ et à la congélation : les activités des extraits étaient mesurées aussitôt après broyage, puis après des temps variables de conservation à $4^{\circ} \mathrm{C}$ ou à $-20^{\circ} \mathrm{C}$. Dans ce dernier cas la décongélation était faite dans un bain thermostaté à $30^{\circ} \mathrm{C}$.

Optimum de température: nous n'avons pas utilisé la méthode cinétique dans ce cas, car les résultats seraient faussés par une interférence entre une activation brève qui peut durer le temps du dosage ( $3 \mathrm{~min}$ ) et l'inactivation thermique due au chauffage, et l'on obtenait des températures optimales fortes $\left(57\right.$ à $\left.60^{\circ} \mathrm{C}\right)$ mais non reliées à celles obtenues par la méthode avec arrêt par le carbonate de K. L'incubation avait lieu en tubes à $43,47,71,55,59$ et $63^{\circ} \mathrm{C}$ pendant $5,10,15$ et $20 \mathrm{~min}$. Les réactions étaient stoppées par le carbonate.

Optimum de $\mathrm{pH}$ et effet du tampon : suivant le $\mathrm{pH}$, on a utilisé différents tampons (acétate-acétique, phosphate de $\mathrm{Na}$, Tris- $\mathrm{HCl}$, collidine- $\mathrm{HCl}$ ). L'ONP libéré a un coefficient d'extinction qui varie avec le $\mathrm{pH}$, ce qui nous a conduit à effectuer les mesures après arrêt des réactions par addition de carbonate de $\mathrm{K}$ (1 M) (lecture à pH 13). 
Constantes cinétiques et inhibition : les activités $\beta$-gal et P- $\beta$-gal ont été déterminées par la méthode cinétique, en utilisant des concentrations de substrat allant de 0,25 à $5 \mathrm{mM}$, additionné ou non de lactose ou de galactose $(10 \mathrm{mM})$, d'isopropyl- $\beta$-D-thiogalactoside $(0,25$ à $10 \mathrm{mM})$, de glucose $(0,5$ à $100 \mathrm{mM})$ et de galactose-6-P $(10 \mathrm{mM})$. En utilisant la méthode des coordonnées inverses de Lineweaver et Burk [17], les affinités des enzymes pour les substrats (mesurées par les $K_{\mathrm{N}}$ ) ont ainsi été déterminées.

Effets de divers composés : le ß-mercapto-éthanol a été testé à la concentration $25 \mathrm{mM}$. Le sulfate d'ammonium était ajouté aux extraits en diluant ces derniers au demi avec une solution 1,7 M de ce sel (concentration finale $0,85 \mathrm{M}$ ). L'activité des extraits était dosée juste après addition et après 24, 48, $96 \mathrm{~h}$ ou $13 \mathrm{j}$ (sulfate d'ammonium $6 \mathrm{mM}$ résiduel dans le mélange réactionnel). Sept solutions salines ont été testées à trois concentrations $(0,5,5$ et $50 \mathrm{mM}$ ) : $\mathrm{MnCl}_{2}, \mathrm{CuSO}_{4}, \mathrm{CaOl}_{2}, \mathrm{Na}_{2} \mathrm{SO}_{4}, \mathrm{KCl}, \mathrm{NaCl}$ et $\mathrm{MgSO}_{4}$.

\section{RESULTATS}

\section{- Culture des souches, température optimale de croissance}

Les 10 souches de $S$. thermophilus utilisées produisent des quantités variables d'acide lactique après $15 \mathrm{~h}$ de culture en milieu M 17 , quantités allant de $4,5 \mathrm{~g} / \mathrm{l}$ à $5,9 \mathrm{~g} / \mathrm{l}$ (tab. 1). Les souches les plus fortes productrices d'acide $(391,308)$ ne sont pas pour autant celles qui permettent d'obtenir les poids de cellules les plus élevés. Notons toutefois que ce poids (culot humide de centrifugation à $13000 \mathrm{~g}$ ) peut être surestimé pour certaines souches si celles-ci synthétisent des polysaccharides qui sédimentent avec les cellules et restent liés à celles-ci malgré les lavages. Ceci peut également expliquer en partie les variations des concentrations en protéines des extraits bruts solubles. L'efficacité du broyage mécanique varie d'ailleurs selon les souches et la présence de polysaccharides peut être au moins une des causes.

La température de culture choisie, $37^{\circ} \mathrm{C}$, a pu favoriser la croissance des souches présentant le caractère mésophile le plus accentué (tab. 1 et [2]). Toutefois, la récolte des cellules s'est faite après la fin de la phase exponentielle, et on peut estimer que la croissance de toutes les souches était maximale dans le milieu M 17 où la concentration en lactose $(5 \mathrm{~g} / 1)$ est très certainement le premier facteur limitant.

\section{- Activités spécifiques $\beta$-gal et $\mathbf{P}$ - $\beta$-gal}

\section{Hydrolyse des substrats synthétiques ONPG et ONPG-6-P}

Les activités spécifiques d'hydrolyse de l'ONPG varient de 1 à 6 selon les souches et les activités spécifiques d'hydrolyse de l'ONPG-6-P 


\section{TABLEAU 1}

Culture des souches de Streptococcus thermophilus en milieu M 17 à $37^{\circ} \mathrm{C}$, teneur en protéines des extraits bruts solubles

et température optimale de croissance

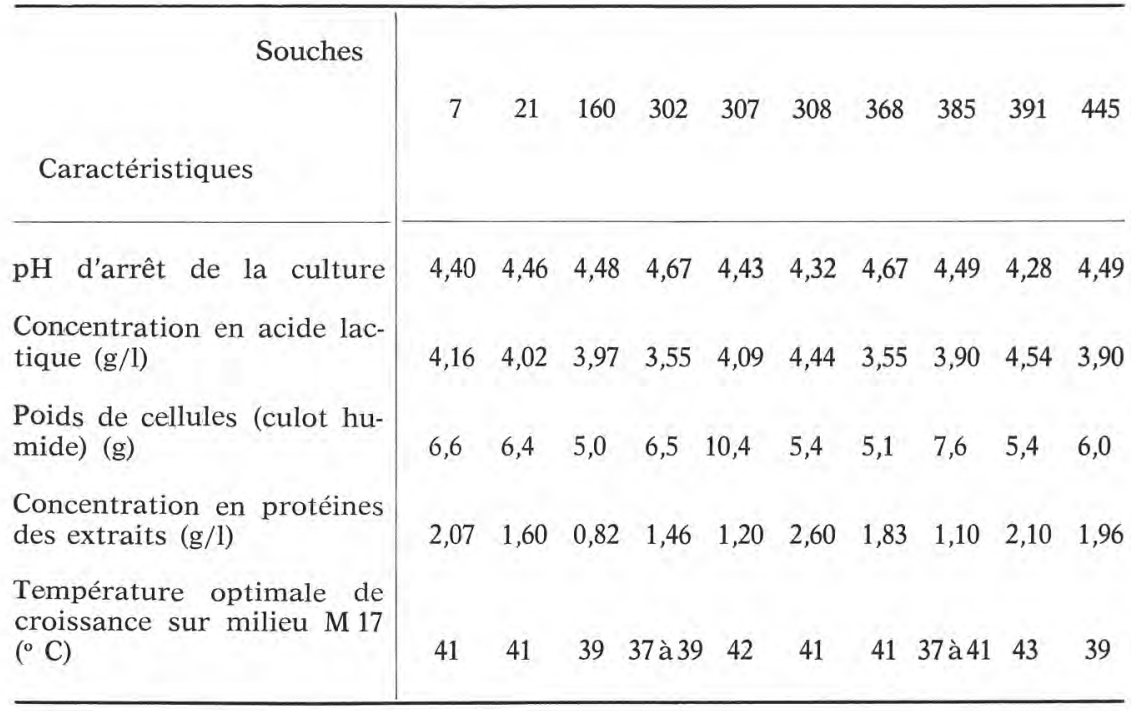

TABLEAU 2

Hydrolyse de l'ONPG, de l'ONPG-6-P et du lactose, et température optimale d'hydrolyse de l'ONPG par les extraits solubles de Streptococcus thermophilus

\begin{tabular}{|c|c|c|c|c|c|c|c|c|c|c|}
\hline \multirow[b]{2}{*}{ Caractéristiques } & \multicolumn{6}{|c|}{ Groupe I } & \multicolumn{3}{|c|}{ Groupe II } & \multirow{2}{*}{$\begin{array}{l}\text { Gr. } \\
\text { III } \\
391\end{array}$} \\
\hline & 302 & 368 & 7 & 307 & 445 & 21 & 308 & 160 & 385 & \\
\hline $\begin{array}{l}\text { A.S. (1) ONPG (U/mg) (p. } 100 \\
\text { de la plus forte) }\end{array}$ & $\begin{array}{c}3,5 \\
(100)\end{array}$ & $\begin{array}{l}3,2 \\
(91)\end{array}$ & $\begin{array}{l}3,1 \\
(89)\end{array}$ & $\begin{array}{l}3,1 \\
(89)\end{array}$ & $\begin{array}{l}3,1 \\
(88)\end{array}$ & $\begin{array}{l}2,8 \\
(80)\end{array}$ & $\begin{array}{l}1,6 \\
(45)\end{array}$ & $\begin{array}{l}1,5 \\
(42)\end{array}$ & $\begin{array}{l}1,3 \\
(37)\end{array}$ & $\begin{array}{c}0,6 \\
(17)\end{array}$ \\
\hline $\begin{array}{l}\text { A.S. (1) ONPG-6-P (U/mg) et } \\
\text { p. } 100 \text { de la plus forte }\end{array}$ & $\begin{array}{l}4,9 \\
(93)\end{array}$ & $\begin{array}{l}5,1 \\
(96)\end{array}$ & $\begin{array}{r}4,3 \\
(81)\end{array}$ & $\begin{array}{r}4,9 \\
(94)\end{array}$ & $\begin{array}{c}5,3 \\
(100)\end{array}$ & $\begin{array}{l}4,4 \\
(21)\end{array}$ & $\begin{array}{l}3,3 \\
(63)\end{array}$ & $\begin{array}{l}3,0 \\
(57)\end{array}$ & $\begin{array}{l}2,7 \\
(51)\end{array}$ & $\begin{array}{l}1,5 \\
(28)\end{array}$ \\
\hline Rapport A.S. ONPG/ONPG-6-P & 1,40 & 1,59 & 1,40 & 1,59 & 1,70 & 1,55 & 2,09 & 2,04 & 2,06 & 2,43 \\
\hline $\begin{array}{l}\text { A.S. lactose (1) (mU/mg) et } \\
\text { p. } 100 \text { de la plus forte }\end{array}$ & $\begin{array}{l}582 \\
(61)\end{array}$ & $\begin{array}{l}557 \\
(58)\end{array}$ & $\begin{array}{l}426 \\
(44)\end{array}$ & $\begin{array}{l}637 \\
(66)\end{array}$ & $\begin{array}{l}43 \\
(4)\end{array}$ & $\begin{array}{l}491 \\
(51)\end{array}$ & $\begin{array}{l}465 \\
(48)\end{array}$ & $\begin{array}{l}175 \\
(18)\end{array}$ & $\begin{array}{l}202 \\
(21)\end{array}$ & $\begin{array}{c}961 \\
(100)\end{array}$ \\
\hline Rapport A.S. ONPG/lactose & 6,0 & 5,7 & 7,3 & 4,9 & 72 & 5,7 & 3,4 & 8,5 & 6,5 & 0,6 \\
\hline $\begin{array}{l}\text { Température optimale d'hy- } \\
\text { drolyse de l'ONPG }\left({ }^{\circ} \mathrm{C}\right)\end{array}$ & 51,5 & 51,5 & 52,5 & 51,5 & 53 & 50,5 & 53 & 49,5 & 50,5 & 49 \\
\hline
\end{tabular}

(1) A.S. = activité spécifique d'hydrolyse des substrats ortho-nitro-phényl- $\beta$-Dgalactoside (ONPG), ortho-nitro-phényl- $\beta$-D-6-phospho-galactoside (ONPG-6-P) et lactose. 
de 1 à 17 (tab. 2). En éliminant les souches dont l'activité est exceptionnellement faible (391 pour $\beta$-gal et 368 pour P- $\beta$-gal), les variations sont respectivement de 1 à 2,7 et de 1 à 3,8 .

On peut distinguer trois groupes de souches selon que les activités sont fortes (groupe I), moyennes (groupe II) ou faibles (groupe III).

Le rapport de l'activité spécifique $\beta$-gal à l'activité spécifique P-B-gal varie de 1,4 pour la souche 302 à 2,43 pour la souche 391 .

\section{Hydrolyse du lactose}

Cette activité est très voisine pour 5 des souches du groupe I et pour la souche 308 du groupe II, les deux autres souches du groupe II (160 et 385) ayant une activité voisine (tab. 2). Pour l'ensemble des souches, l'activité spécifique d'hydrolyse varie de 1 à 25 en raison de l'activité exceptionnellement faible de la souche 445 et de la forte activité de la souche 391 . L'écart se réduit à 1,5 si on élimine ces 2 souches. Le rapport de l'activité d'hydrolyse de l'ONPG à l'activité d'hydrolyse du lactose varie de 1 (souche 391) à 83 (souche 445). Elle est le plus souvent comprise entre 3,4 et 8,5 .

\section{Température optimale d'action des $\beta$-galactosidases}

La figure 1 représente l'activité $\beta$-gal des différentes souches en fonction de la température. On a pris pour base 100 l'activité obtenue à la température optimale. Sur la figure, pour faciliter la présentation, on a décalé les ordonnées d'une valeur égale à 10 p. 100 d'une souche à l'autre.

L'activité $\beta$-gal est optimale à des températures allant de $49^{\circ} \mathrm{C}$ pour la souche 391 à $53^{\circ} \mathrm{C}$ pour les souches 445 et 308 (fig. 1). L'écart entre les températures pour lesquelles ont détecte $80 \mathrm{p} .100$ de l'activité maximale varie de $7,5^{\circ} \mathrm{C}$ pour la souche 385 à $13,4^{\circ} \mathrm{C}$ pour la souche 302 , cet écart étant le plus souvent de 9 à $10^{\circ} \mathrm{C}$. Les souches des groupes II et III, sauf la souche 308 , ont un optimum bas (de 49 à $50,5^{\circ} \mathrm{C}$ ) alors que celles du groupe I, la souche 21 mise à part, ont un optimum élevé (de 51 à $53^{\circ} \mathrm{C}$ ). Enfin la souche 385 est la seule qui présente un épaulement vers $35-40^{\circ} \mathrm{C}$.

\section{- Stabilité des $\beta$-gal et P- $\beta$-gal}

\section{Stabilité à $4^{\circ} \mathrm{C}$}

L'activité des extraits bruts solubles est relativement stable à $4^{\circ} \mathrm{C}$ (tab. 3). La souche 308 mise à part, les 9 autres souches conservent au moins 70 p. 100 de leur activité après $21 \mathrm{j}$ de conservation à cette température. Des extraits congelés, décongelés et conservés à $4^{\circ} \mathrm{C}$ présentent une stabilité comparable, indépendamment de la perte subie à la congélation. 


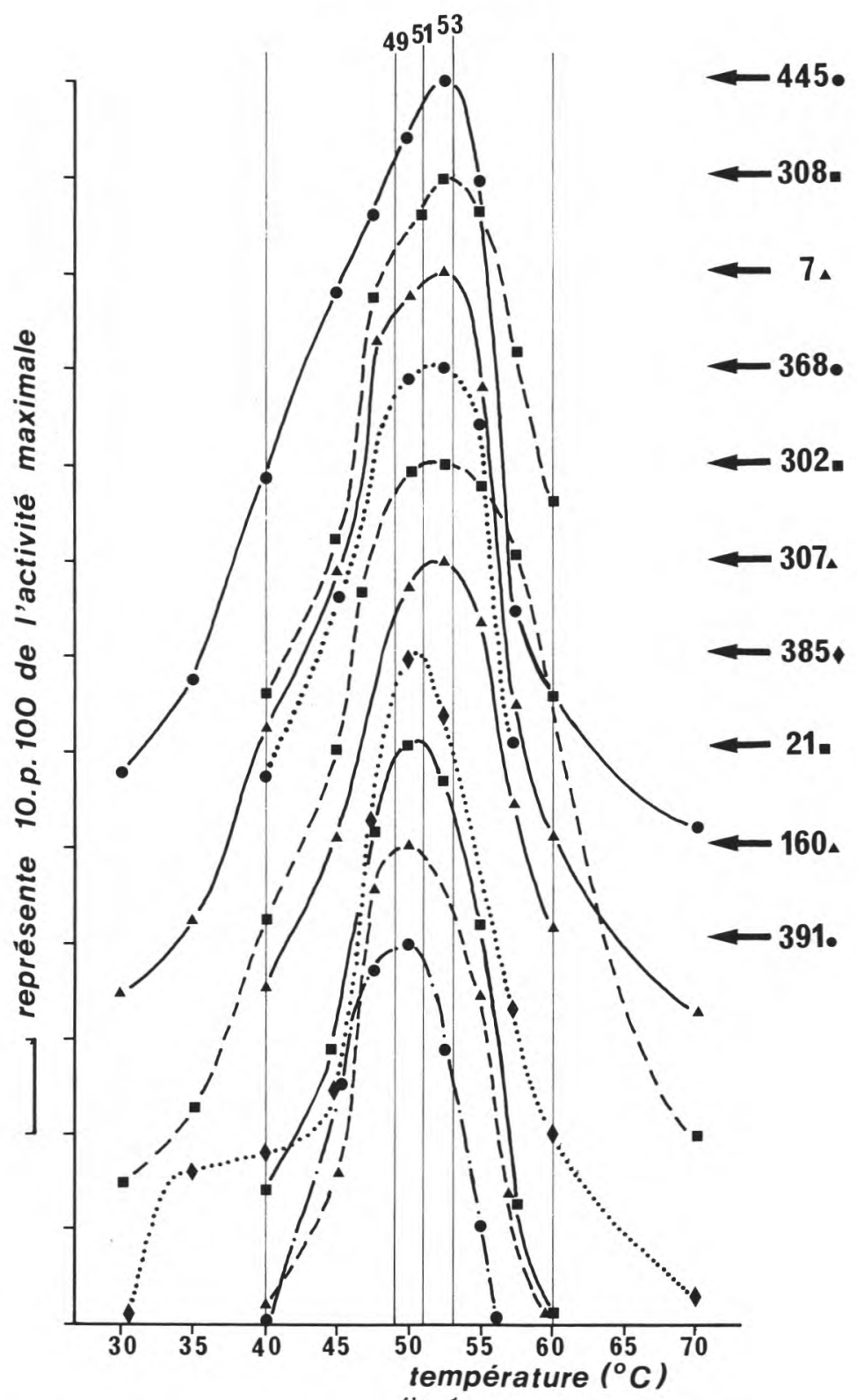

fig. 1

Activités des $\beta$-galactosidases de 10 souches de Streptococcus thermophilus en fonction de la température

L'activité était mesurée en tampon phosphate de $\mathrm{Na}(50 \mathrm{mM}, \mathrm{pH}$ 6,7) contenant de l'ONPG $(5 \mathrm{mM})$. La réaction était arrêtée après $10 \mathrm{~min}$ d'incubation à la température désirée par addition de carbonate de $\mathrm{K}$ $(1 \mathrm{M})$. Les numéros sur la partie droite de la figure sont ceux des 10 souches. Les flèches indiquent les maximums d'activité. Ceux-ci sont décalés de 10 p. 100 de l'activité maximale d'une souche à l'autre, pour la clarté de la figure. 
TABLEAU 3

Stabilité des $\beta$-galactosidases de Streptococcus thermophilus conservées au froid, congelées ou non

\begin{tabular}{|c|c|c|c|c|c|c|c|c|c|c|c|}
\hline \multirow[b]{2}{*}{ Traitements } & \multirow[t]{2}{*}{ Souches } & \multicolumn{6}{|c|}{ Groupe I } & \multicolumn{3}{|c|}{ Groupe II } & \multirow{2}{*}{$\begin{array}{l}\text { Gr. } \\
\text { III } \\
391\end{array}$} \\
\hline & & 302 & 368 & 7 & 307 & 445 & 21 & 308 & 160 & 385 & \\
\hline $21 \mathrm{j}$ à $\quad 4^{\circ} \mathrm{C}$ & (1) & 78 & 91 & 78 & 74 & 85 & 80 & 49 & 92 & 70 & 85 \\
\hline $21 \mathrm{j}$ à $-20^{\circ} \mathrm{C}$ & (1) & 34 & 23 & 31 & 27 & 32 & 25 & 21 & 24 & 32 & 35 \\
\hline 1 an à $-20^{\circ} \mathrm{C}$ & (1) & 6 & 6 & 5 & 4 & 8 & 9 & 8 & 12 & 16 & 5 \\
\hline \multicolumn{2}{|l|}{ Effet de } & & & & & & & & & & \\
\hline $\mathrm{SO}_{4}\left(\mathrm{NH}_{4}\right)_{2}$ & $\beta$-gal & 62 & 67 & 88 & 55 & 88 & 78 & 90 & 40 & 75 & 77 \\
\hline $\begin{array}{l}0,85 \mathrm{M} \\
\text { (2) }\end{array}$ & P- $\beta$-gal & 31 & 57 & 47 & 37 & 65 & 71 & 30 & 41 & 35 & 27 \\
\hline
\end{tabular}

(1) Activités spécifiques relatives (en p. 100 de l'activité spécifique mesurée après broyage des cellules) ; (2) Activité résiduelle en p. 100 de l'activité résiduelle des extraits non soumis à l'action du sulfate d'ammonium, après $48 \mathrm{~h}$ à $4^{\circ} \mathrm{C}$.

Stabilité à la congélation-décongélation

Après $21 \mathrm{j}$ de stockage à $-20^{\circ} \mathrm{C}$, l'activité $\beta$-gal et l'activité P-p-gal restent élevées. Lorsque le temps de conservation est plus long (1 an), la perte est totale pour quelques souches. Elle l'est pour toutes les souches après 3 ans. Ce sont généralement les extraits dont l'activité était la plus forte après broyage qui conservent le mieux leur activité.

\section{Résistance au chauffage}

Un chauffage de 5 min à $59^{\circ} \mathrm{C}$ entraîne une perte d'activité $\beta$-gal variable selon les souches (fig. 2 a). La souche 391 (groupe III) est la plus sensible. Trois souches du groupe I et la souche $308 \mathrm{du}$ groupe II sont les plus résistantes à ce traitement.

L'activité P-B-gal diminue le plus souvent, pour une souche donnée, dans les mêmes proportions que l'activité $\beta$-gal (fig. 2 b). Notons aussi que la P- $\beta$-gal de la souche 385 est très affectée puisqu'un chauffage court $(1 \mathrm{~min})$ entraîne une perte d'activité de 50 p. 100 .

La souche 391 particulièrement labile mise à part, 4 autres souches conservent au moins 75 p. 100 d'activité après un chauffage de 15 min à $55^{\circ} \mathrm{C}$ (fig. 3 ). La souche 445 est activée par ce chauffage ; 


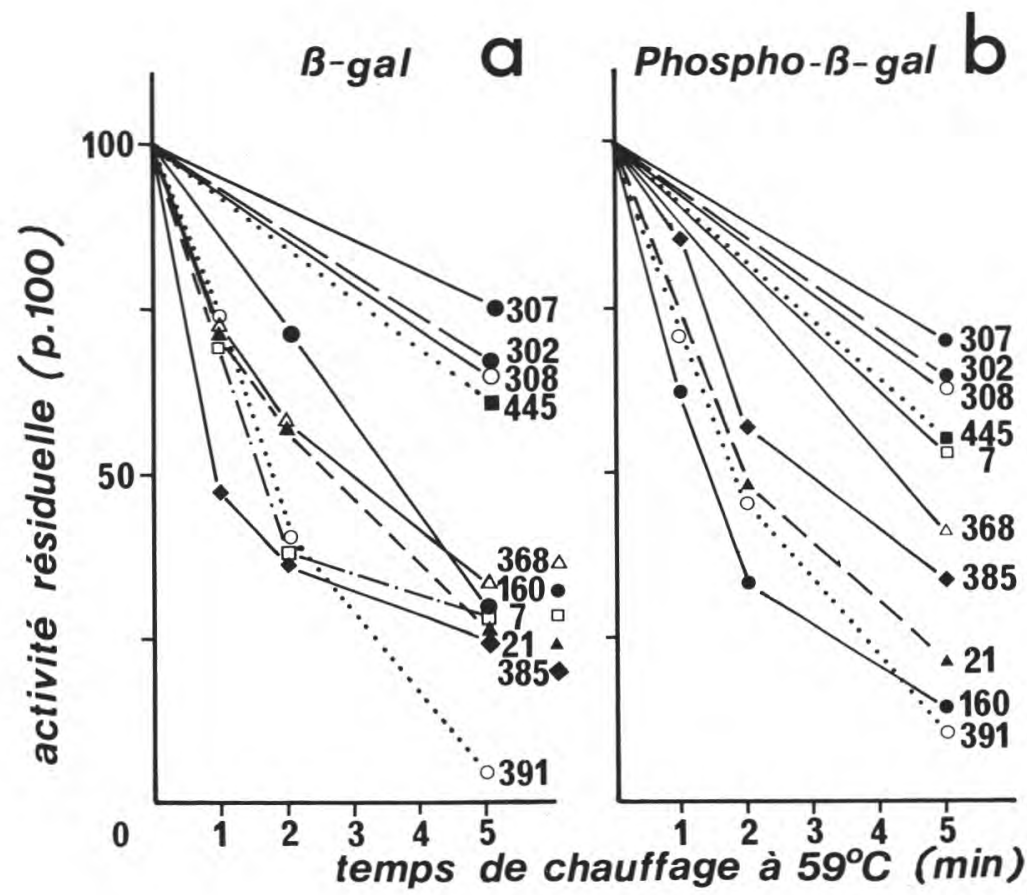

fig. 2

Stabilité thermique des $\beta$-galactosidases (fig. 2 a) et des P- $\beta$-galactosidases (fig. $2 \mathrm{~b}$ ) de 10 souches de Streptococcus thermophilus, soumises à un chauffage à $59^{\circ} \mathrm{C}$ pendant des durées variables

Les extraits bruts $(1 \mathrm{ml})$ étaient chauffés pendant des temps variables à $59^{\circ} \mathrm{C}$ en tampon phosphate de $\mathrm{Na}(50 \mathrm{mM})$, refroidis rapidement dans la glace fondante. Les mesures d'activité résiduelle étaient faites à $30^{\circ} \mathrm{C}$ par la méthode cinétique (voir matériels et méthodes).

ce comportement est peut-être en relation avec la température optimale d'action élevée $\left(53^{\circ} \mathrm{C}\right)$.

Stabilité vis-à-vis du pH

Après un séjour de $48 \mathrm{~h}$ dans des tampons ajustés à différents $\mathrm{pH}$, on constate que la souche 445 a l'activité la plus stable en tampon Tris- $\mathrm{HCl}$ à $\mathrm{pH}$ basique $(8,3)$. A pH 6,8, la $\beta$-gal perd $50 \mathrm{p} .100$ de son activité en tampon Tris- $\mathrm{HCl}$ et 60 p. 100 en tampon phosphate de $\mathrm{Na}$. Enfin, à $\mathrm{pH}$ 6,2, les activités résiduelles ne sont plus que de 35 p. 100 en tampon phosphate et de 40 p. 100 en tampon acétate.

\section{Stabilité en présence d'ions}

La $\beta$-gal de la souche 302 est stable en présence ide $\mathrm{KCl}$ ( $25 \mathrm{mM}$ ). Elle est instable en présence de $\mathrm{MgSO}_{4}$, son activité chutant de 80 p. 100 


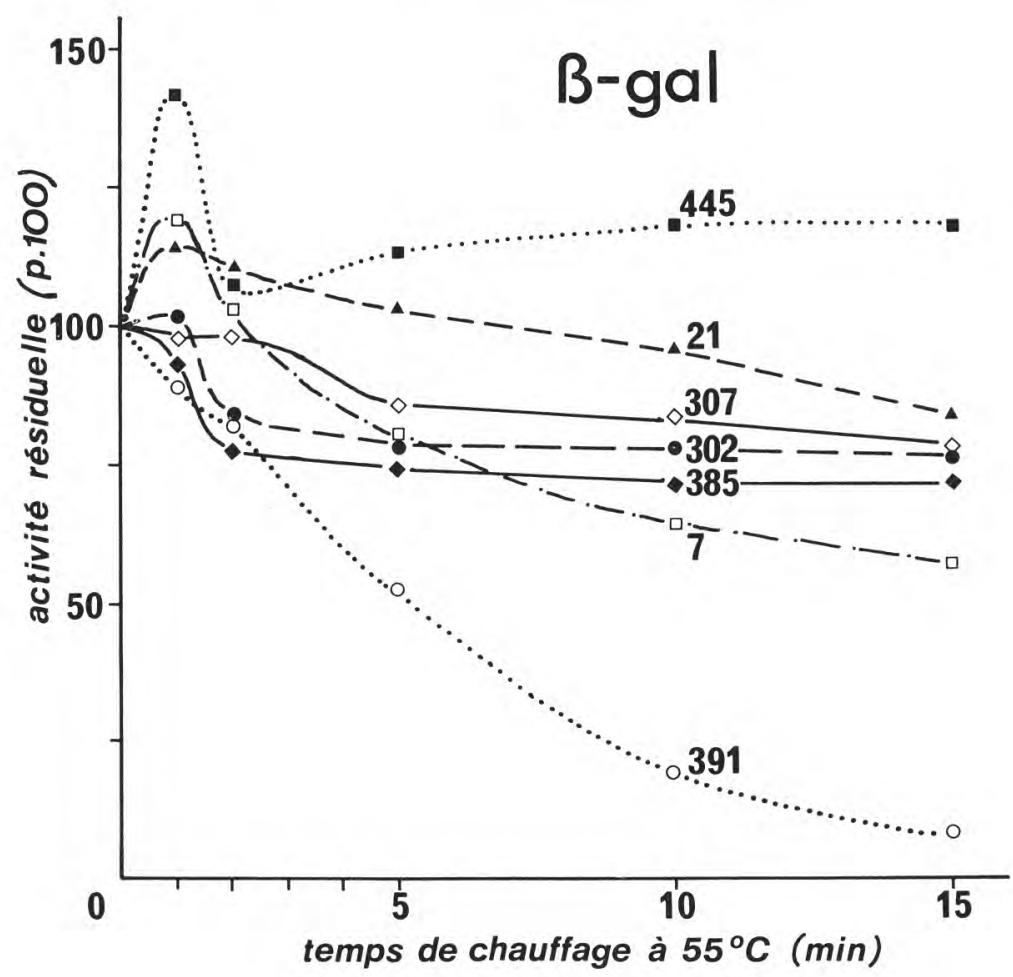

fig. 3

Stabilité thermique des $\beta$-galactosidases de 7 souches de Streptococcus thermophilus soumises à un chauffage à $55^{\circ} \mathrm{C}$ pendant des durées variables

Mode opératoire : voir figure 2 et matériels et méthodes.

après $24 \mathrm{~h}$ à $4^{\circ} \mathrm{C}$. Contrairement à la $\beta$-gal de $S$. lactis 7962, les $\beta$-gal et les P- $\beta$-gal d'aucune des 10 souches de $S$. thermophilus ne sont stabilisées, voire activées, par le sulfate d'ammonium 0,85 M (tab. 3).

\section{- pH optimaux d'action}

Les figures 4 a et $4 \mathrm{~b}$ représentent les activités spécifiques des $\beta$-gal et des $\mathrm{P}$ - $\beta$-gal en fonction du $\mathrm{pH}$. Les zones d'utilisation des trois tampons sont rappelées sur chaque figure (voir méthodes).

En tampon Tris- $\mathrm{HCl}$, toutes les souches ont une activité $\beta$-gal optimale voisine de $\mathrm{pH} 8,5$ (fig. 4 a). L'activité de la souche 307 est la même à $\mathrm{pH} 8$ et à $\mathrm{pH}$ 9. Les activités en tampon phosphate de $\mathrm{Na}$ sont toujours plus faibles qu'en tampon Tris-HCl. Les optimums 

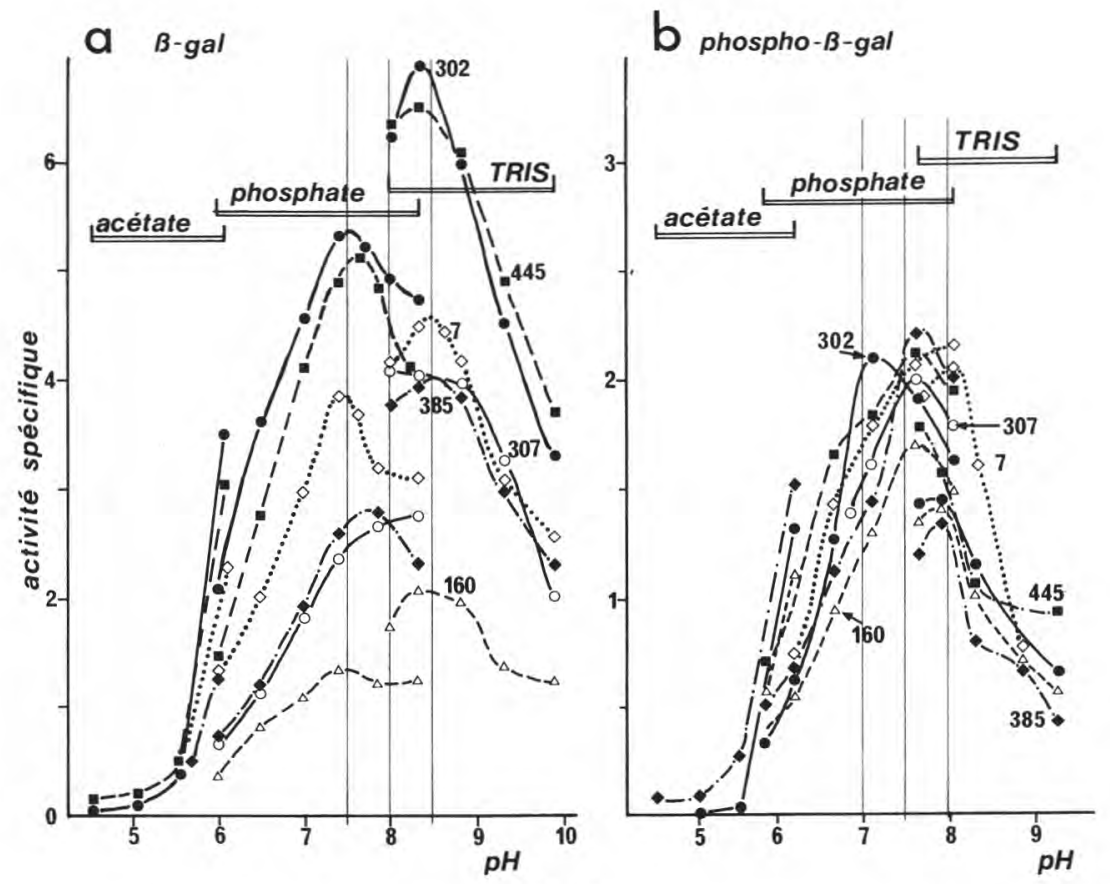

fig. 4

$\mathrm{pH}$ optimaux d'action des $\beta$-galactosidases (fig. 4 a) et des P- $\beta$-galactosidases (fig. 4 ) de 6 souches de Streptococcus thermophilus

Les activités étaient mesurées par la variation de D.O. à $420 \mathrm{~nm}$ après $10 \mathrm{~min}$ d'incubation à $30^{\circ} \mathrm{C}$, en présence de substrats ONPG et ONPG-6-P, dans les tampons $(50 \mathrm{mM})$ acétate-acide acétique, phosphate de $\mathrm{Na}$ ou Tris- $\mathrm{HCl}$.

varient de 7,5 (souches 7 et 302) à 7,7 (autres souches). Pour les souches 21, 302, 368 et 445, l'optimum de $\mathrm{pH}$ en tampon collidine$\mathrm{HCl}$ (non représenté) est de 8,0. Les activités $\beta$-gal en tampon acétateacétique à $\mathrm{pH} 6$ sont environ deux fois plus élevées que celles obtenues dans le tampon phosphate de $\mathrm{Na}$ au même $\mathrm{pH}$.

Contrairement aux activités $\beta$-gal, les activités P- $\beta$-gal sont plus fortes en tampon phosphate de $\mathrm{Na}$ qu'en tampon Tris- $\mathrm{HCl}$ (fig. $4 \mathrm{~b}$ ). Le pH optimal est 7,6 pour 6 des 8 souches représentées. La souche 302 a une activité optimale à $\mathrm{pH} 7,2$ alors que la souche 7 ne présente pas d'optimum net (max. à $\mathrm{pH} 8,1$ ). En tampon Tris- $\mathrm{HCl}$, le $\mathrm{pH}$ optimal se situe, selon les souches, entre $\mathrm{pH} 7,7$ et $\mathrm{pH} 8,1$. L'activité à pH 6 en tampon acétate-acétique est, comme pour la $\beta$-gal, deux fois plus élevée que celle obtenue en tampon phosphate de $\mathrm{Na}$, au même $\mathrm{pH}$. 


\section{- Activités catalytiques des $\beta$-gal et P- $\beta$-gal}

Conditions optimales d'hydrolyse des substrats synthétiques

Dans les conditions expérimentales de dosages choisies (voir matériels et méthodes), en utilisant des dilutions d'extraits telles que la variation de D.O. à $420 \mathrm{~nm}$ soit inférieure à 0,100 unité de D.O. $/ 2 \mathrm{~min}$, la concentration en ONPG (ONPG-6-P) utilisée, $5 \mathrm{mM}$, est saturante pour toutes les enzymes. Les vitesses d'hydrolyse sont de l'ordre de 50 p. 100 si la concentration du substrat est de $1 \mathrm{mM}$. Le tampon phosphate de $\mathrm{Na}$ choisi est vraisemblablement celui qui représente au mieux les conditions où se trouvent les enzymes au sein des cellules.

\section{Effet de divers ions}

Les ions phosphate réduisent d'environ 30 p. 100 l'activité $\beta$-gal, mais activent les $\mathrm{P}-\beta$-gal de 20 p. 100 . L'ion $\mathrm{Na}^{+}$ne semble pas être la cause de l'inhibition des $\beta$-gal puisque l'addition de $\mathrm{NaCl}(25 \mathrm{mM})$ à ce même tampon provoque une activation de 19 p. 100 (souche 302). L'ion $\mathrm{Cl}^{-}$exerce un effet stabilisant sur l'activité $\beta$-gal qui est observé avec $\mathrm{KCl}$ ou $\mathrm{MnCl}_{2}(25 \mathrm{mM})$ et avec les tampons Tris- $\mathrm{HCl}$ ou collidine$\mathrm{HCl}(50 \mathrm{mM})$. Les ions $\mathrm{Cu}^{++}$et $\mathrm{Ca}^{++}$inhibent la $\beta$-gal de la souche 302. Il en est de même pour les ions $\mathrm{SO}_{4}{ }^{=}$, l'effet de ces derniers pouvant être accentué $\left(\mathrm{CuSO}_{4}\right)$ ou diminué $\left(\mathrm{Na}_{2} \mathrm{SO}_{4}\right.$ ou $\left.\mathrm{MgSO}_{4}\right)$.

L'effet de $\mathrm{MgSO}_{4}(25 \mathrm{mM})$ sur les activités $\beta$-gal et P- $\beta$-gal varie selon les souches (tab. 4). Les activités des deux enzymes de la souche 445 sont les plus sensibles à ce sel. En présence de sulfate d'ammonium, on note une inhibition de toutes les activités, allant de 9 à 52 p. 100 pour les $\beta$-gal et de 24 à 70 p. 100 pour les P- $\beta$-gal (tab. 4 ).

Le $\beta$-mercapto-éthanol exerce un effet activateur plus ou moins marqué sur la $\beta$-gal et la $P$ - $\beta$-gal des différentes souches (211 à 438 p. 100 pour les $\beta$-gal et 260 à 560 p. 100 pour les $P-\beta$-gal ; voir tab. 4).

\section{Cinétique d'hydrolyse des substrats}

L'affinité des $\beta$-gal pour l'ONPG varie selon les souches. Elle est exprimée dans le tableau 5 sous forme de $\mathrm{K}_{\mathrm{m}}$ (constante de MichaelisMenten, dont la grandeur est inversement proportionnelle à l'affinité). L'affinité des $\beta$-gal des souches 302 et 391 est forte ( $K_{\mathrm{M}}$ voisins de $0,16 \mathrm{mM})$, celle de la souche 307 est faible $\left(\mathrm{K}_{\mathrm{M}}=0,84 \mathrm{mM}\right)$. Les affinités des $\beta$-gal des autres souches sont de l'ordre de 0,2 mM.

L'affinité des $\beta$-gal pour le lactose a été mesurée pour la souche 302. La valeur $\mathrm{K}_{\mathrm{m}}$ trouvée, $22 \mathrm{mM}$, indique que cette enzyme présente une affinité quatorze fois plus grande pour ce substrat naturel que pour le substrat synthétique ONPG. Notons par ailleurs qu'on observe pour toutes les souches un phénomène d'inhibition par excès de substrat lorsque celui-ci est l'ONPG, qu'il soit seul ou associé à d'autres substrats ou à des inhibiteurs (cf. l'exemple de la souche 302, fig. 4). Cette inhibition n'apparaît pas avec le lactose. 


\section{TABLEAU 4}

Effet de diverses substances sur la $\beta$-galactosidase et la $\mathrm{P}-\beta$-galactosidase de Streptococcus thermophilus

\begin{tabular}{|c|c|c|c|c|c|c|c|c|c|c|c|}
\hline \multirow[b]{2}{*}{ Ions } & \multirow[t]{2}{*}{ Souches } & \multicolumn{6}{|c|}{ Groupe I } & \multicolumn{3}{|c|}{ Groupe II } & \multirow{2}{*}{$\begin{array}{l}\text { Gr. } \\
\text { III } \\
391\end{array}$} \\
\hline & & 302 & 368 & 7 & 307 & 445 & 21 & 308 & 160 & 385 & \\
\hline \multirow{2}{*}{$\mathrm{MgSO}_{4}$} & $\beta$-gal & 69 & 147 & 138 & 138 & 90 & 109 & 238 & 275 & 133 & ND \\
\hline & P- $\beta$-gal & 136 & 209 & 189 & 211 & 77 & 200 & 314 & 167 & ND & 314 \\
\hline \multirow{2}{*}{$\mathrm{SO}_{4}\left(\mathrm{NH}_{4}\right)_{2}$} & $\beta$-gal & 59 & 59 & 64 & 78 & 65 & 69 & 89 & 91 & 60 & 75 \\
\hline & P- $\beta$-gal & 45 & 59 & 41 & 44 & 76 & 73 & 30 & 43 & 30 & 52 \\
\hline \multirow{2}{*}{$\beta$-mercapto-éthanol } & $\beta$-gal & 211 & 388 & 438 & 255 & 358 & 259 & 229 & 220 & 430 & ND \\
\hline & P- $\beta$-gal & 264 & 336 & 78 & 289 & 292 & 389 & 528 & 567 & ND & 533 \\
\hline
\end{tabular}

Les activités sont exprimées en p. 100 des activités obtenues sans addition des diverses substances. Elles ont été mesurées dès l'addition des divers composés. Les résultats sont donc différents de ceux obtenus, pour le sulfate d'ammonium, après conservation en présence de ce sel (tab. 3).

\section{TABLEAU 5}

Constantes cinétiques des $\beta$-galactosidases de 10 souches de Streptococcus thermophilus

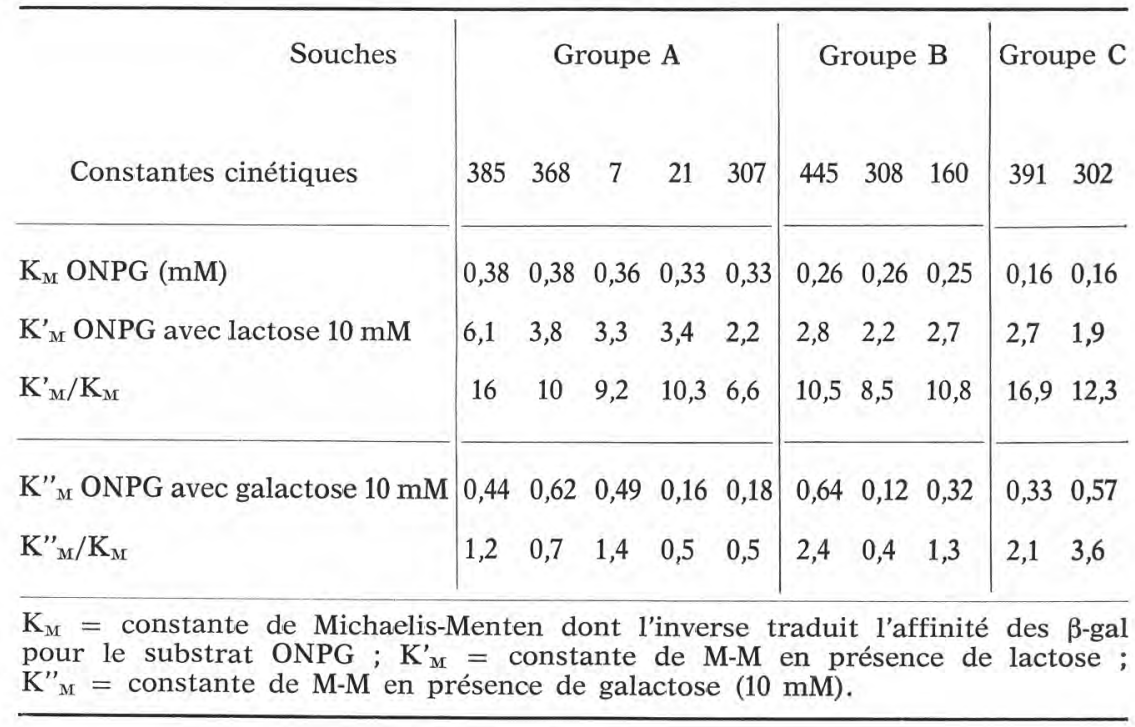




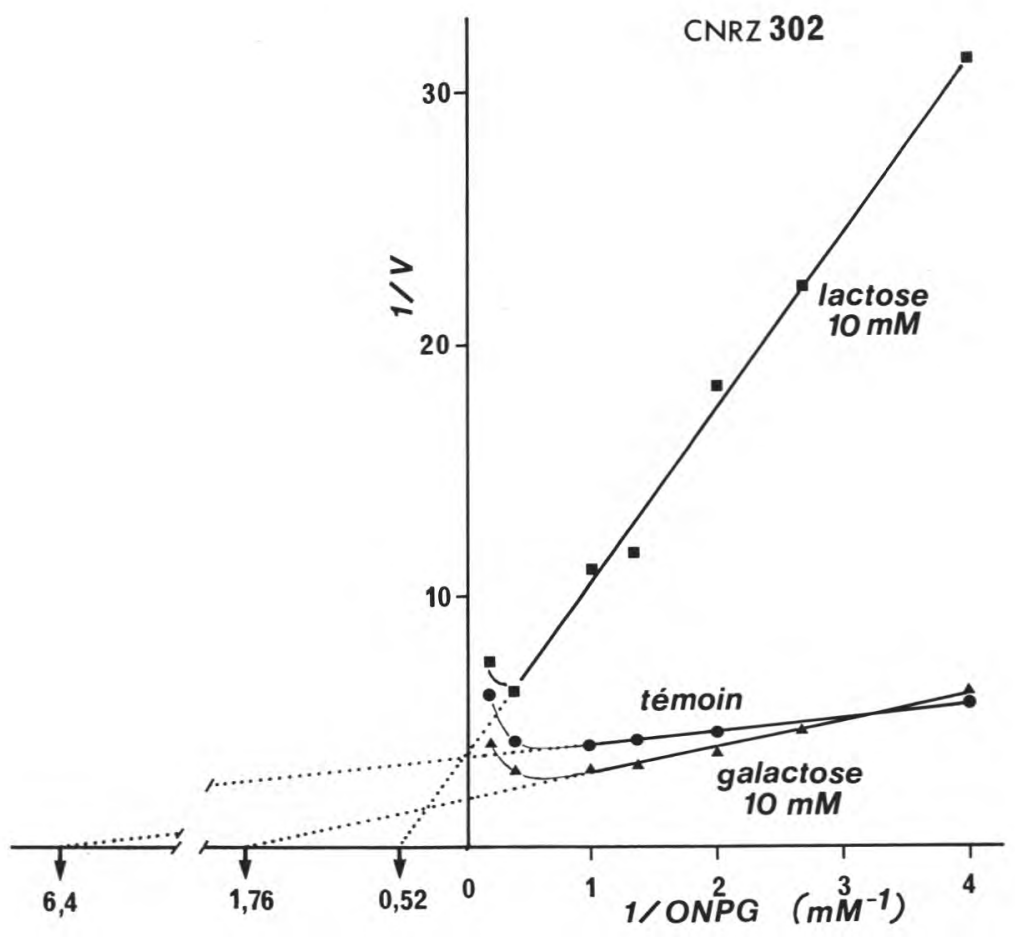

fig. 5

Activité de la $\beta$-galactosidase de Streptococcus thermophilus CNRZ 302 en fonction de la concentration d'ONPG. Effet de l'addition de lactose ou de galactose $(10 \mathrm{mM})$ au mélange réactionnel

Représentation en coordonnées inverses selon Lineweaver et Burk [17]. Les mesures étaient effectuées par la méthode cinétique (voir matériels et méthodes).

L'affinité pour l'ONPG-6-P a été déterminée uniquement dans le cas de la souche 385 . Elle est plus faible que l'affinité correspondante de la $\beta$-gal de la même souche $\left(\mathrm{K}_{\mathrm{m}}=6,6 \mathrm{mM}\right)$.

Compétition entre substrats pour les $\beta$-gal

Le lactose se comporte comme un inhibiteur compétitif vis-à-vis de l'ONPG pour toutes les $\beta$-gal, comme cela est illustré par la figure 5 dans le cas de la souche 302. Les $\mathrm{K}_{\mathrm{M}}$ obtenues en présence de lactose $(10 \mathrm{mM})$ indiquent des affinités généralement dix fois plus faibles qu'en absence de lactose (tab. 5). Les souches 385, 302 et 391 sont les plus affectées. Cela peut s'expliquer pour les souches 302 et 391 par leur forte affinité pour l'ONPG. Par contre, la souche 385 présente un comportement singulier. Enfin, la souche 307 qui 
n'avait que peu d'affinité pour l'ONPG, ne subit qu'une réduction de 2,6 fois de cette affinité en présence de lactose $(10 \mathrm{mM})$.

\section{Action d'analogues de substrats}

Il était loisible de penser que le galactose inhiberait la $\beta$-gal puisque cette enzyme hydrolyse des $\beta$-galactosides. Or, le galactose $(10 \mathrm{mM})$ n'exerce qu'une action modérée sur les cinétiques d'hydrolyse de I'ONPG (tab. 5). En effet, il se comporte parfois comme un inhibiteur compétitif et parfois comme un activateur, entraînant dans ce dernier cas une augmentation de la vitesse maximale d'hydrolyse et une augmentation de l'affinité ( $\mathrm{K}^{\prime \prime}$ s plus faibles), par exemple dans le cas de la souche 302 (fig. 5).

Par contre le glucose active à la fois les $\beta$-gal et le P- $\beta$-gal, et cela quelle que soit sa concentration (de 0,5 à $100 \mathrm{mM}$ ). Ce comportement s'expliquerait par le manque de spécificité de ces tiıymes qui présentent une affinité pour des oses dont la conformation stérique s'éloigne des $\beta$-galactosides. De même le galactose-6-phosphate $(10 \mathrm{mM})$ active les deux enzymes.

L'isopropyl- $\beta$-D-thiogalactoside, analogue dans lequel la liaison éther-oxyde est remplacée par une liaison thio-éther, inhibe rapidement la $\beta$-gal des souches 445 et 302 . Par contre, à faible concentration, ce composé active la P- $\beta$-gal de la souche 445 alors qu'à des concentrations plus fortes (5 à $10 \mathrm{mM}$ ), il devient inhibiteur. Enfin l'extrait de la souche 302 hydrolyse l'alpha-ONPG, ce qui témoigne à nouveau de la faible spécificité de l'enzyme.

\section{DISCUSSION}

\section{Discussion de la méthodologie}

Cette étude, effectuée sur 10 souches, nous a permis de préciser certaines propriétés des enzymes $\beta$-gal et P- $\beta$-gal de $S$. thermophilus. Les conclusions figées de l'étude d'une seule souche font fréquemment l'objet de généralisations hâtives au niveau de l'espèce ; c'est par exemple le cas pour $S$. thermophilus [27, 28, 37] et pour d'autres streptocoques $[13,14]$. L'étude de la fermentation du lactose par S. lactis est, à ce titre, exemplaire. S. lactis 7962, qui a été étudiée intensivement, diffère notablement des autres souches de streptocoques lactiques mésophiles, à l'exception de la souche isolée récemment par Farrow et Garvie [7]. En outre, S. lactis 7962 se développe lentement dans le lait [33], ce qui limite singulièrement son utilisation en technologie.

D'autre part, les " activités » $\beta$-gal et P- $\beta$-gal ont été fréquemment mesurées après avoir traité les cellules au toluène pour les rendre perméables aux substrats étudiés, ONPG ou ONPG-6-P $[4,14,15,21$, $24,37]$. L'utilisation d'extraits bactériens bruts, contenant les enzymes 
solubles, permet d'exprimer les activités spécifiques des enzymes, rapportées à la concentration en protéines $[6,12,21,23]$.

Enfin, l'hydrolyse du lactose a souvent été délaissée par les auteurs au profit de l'hydrolyse des substrats synthétiques ONPG et ONPG-6-P $[8,16,23,24,26,28]$ qui présentent plus d'affinité pour la $\beta$-gal. Dans le cas de $S$. thermophilus, l'affinité de la $\beta$-gal est effectivement plus forte pour l'ONPG que pour le lactose. Nous n'avons pas trouvé chez cette espèce, comme c'est le cas pour d'autres genres $[8,29]$, de souches dont la $\beta$-gal n'hydrolyse que l'ONPG. Le rapport de l'activité d'hydrolyse de l'ONPG à l'activité d'hydrolyse du lactose peut d'ailleurs constituer un critère utile pour différencier les $\beta$-gal des diverses souches. Il est d'autre part préférable de déterminer les constantes cinétiques $\left(K_{M}, K_{M}^{\prime}, K^{\prime \prime}{ }_{M}\right)$ à l'aide des extraits bruts, bien que des contaminants présents dans ceux-ci puissent avoir une certaine influence. En effet, l'activité spécifique telle qu'elle a souvent été mesurée $[22,23,37]$, ne se réfère qu'à une seule concentration en substrat, même si celle-ci a été par exemple choisie à dessein, telle une teneur en lactose équivalente à celle du lait [38].

\section{Discussion des résultats}

\section{Propriétés des enzymes de S. thermophilus}

Les 10 souches de $S$. thermophilus étudiées présentent toutes des activités vis-à-vis de l'ONPG et de l'ONPG-6-P, et celles-ci sont du même ordre de grandeur pour une souche donnée, ce qui confirme les résultats préliminaires obtenus pour deux souches [12]. La $\beta$-gal et la P- $\beta$-gal ont en outre des propriétés similaires, telles que l'inactivation thermique, l'induction selon les conditions de culture, de $\mathrm{pH}$ notamment [12], la mobilité électrophorétique [9]. Cela suggère l'existence d'au moins deux isoenzymes, de spécificité large, pouvant hydrolyser tout aussi bien des $\beta$-galactosides que des 6-phospho- $\beta$ galactosides voire un $\alpha$-galactoside tel que l' $\alpha$-ONPG.Le lactose ( $\beta$-galactoside) est d'ailleurs un inhibiteur compétitif à la fois de l'ONPG ( $\beta$-galactoside) et de l'ONPG-6-P (6-P- $\beta$-galactoside). Toutefois, l'affinité du lactose pour ces enzymes est beaucoup plus faible (cent fois dans le cas de $S$. thermophilus), comme cela a été classiquement montré pour les $\beta$-gal d'autres organismes (voir in [36]). Nous n'avons malheureusement pas pu mesurer l'hydrolyse du lactose-phosphate (6-phospho- $\beta$-galactosyl-glucose) qui n'est pas commercialisé. Ce composé a été mis en évidence récemment par Thompson [34] chez $S$. lactis, et, par analogie, on peut penser qu'il constitue le substrat normal de la P- $\beta$-gal de S. thermophilus.

Nous avions montré précédemment que la $\beta$-gal et la P- $\beta$-gal étaient induites fortement à bas $\mathrm{pH}$ chez $S$. thermophilus [12]. Les extraits utilisés dans cette étude proviennent de cultures arrêtées à $\mathrm{pH}$ bas (inférieurs à 5). Les activités spécifiques mesurées représentent donc très certainement les quantités d'enzymes maximales que 
les cellules peuvent synthétiser. Il est possible que les extraits présentant les plus fortes activités (par exemple les extraits des souches du groupe I) pour la $\beta$-gal et la P- $\beta$-gal soient ceux de souches facilement inductibles. Mais on peut remarquer que ce ne sont pas les extraits de souches dont la culture a été arrêtée aux $\mathrm{pH}$ les plus bas qui ont pour autant les plus fortes activités spécifiques.

Les activités spécifiques $\beta$-gal et P- $\beta$-gal mesurées ne peuvent pas toujours être reliées aux constantes cinétiques de ces enzymes. Cependant on peut noter que la souche 302 possède à la fois la plus forte activité et la plus grande affinité pour l'ONPG. La souche 385 possède une très forte affinité pour le lactose car, en présence de ce sucre, l'affinité pour l'ONPG diminue beaucoup plus que pour les autres souches. Cela pourrait expliquer la faible induction de la $\beta$-gal chez cette souche à bas $\mathrm{pH}$, contrairement à ce qui existe chez la souche 302 [12].

La température optimale d'action de la $\beta$-gal n'est pas en relation avec la température optimale de culture des souches sur milieu M 17.

Certaines $\beta$-gal dont les affinités pour l'ONPG sont voisines ont la même résistance au chauffage ( 445 et 308 , ou 385 et 368 ), d'autres non (302 et 391). De même, les $\beta$-gal dont la température optimale d'action est basse (groupe II) sont les plus thermolabiles, ces deux caractéristiques étant probablement liées. Ces $\beta$-gal thermolabiles ont par ailleurs les plus fortes activités d'hydrolyse du lactose. L'optimum de $\mathrm{pH}$ de la P- $\beta$-gal de la souche 302 pourrait expliquer la production d'acide élevée de cette souche cultivée sur lait. La souche 385, dont les caractéristiques ont été rappelées plus haut, a des activités $\beta$-gal et P- $\beta$-gal optimales aux mêmes $\mathrm{pH}$ que celles des autres souches. La forte production d'acide qu'elle est capable de faire n'est donc certainement pas due à un optimum de $\mathrm{pH}$ plus bas de ses enzymes. La souche de $S$. thermophilus étudiée par Rao et Dutta [28] a une température optimale d'action $\left(55^{\circ} \mathrm{C}\right)$ plus élevée que celles de nos souches, ainsi qu'une résistance au chauffage plus grande et un $\mathrm{pH}$ optimal plus bas $(6,8)$. Par contre $S$. thermophilus C 12, étudiée par Wierzbicki et Kosikowski [37] a une activité d'hydrolyse du lactose (et non de l'ONPG) optimale entre $\mathrm{pH} 5,5$ et 6,5 et une température optimale entre 35 et $50^{\circ} \mathrm{C}$, mais ces valeurs furent déterminées avec des cellules entières.

Les souches de $S$. thermophilus dont la production d'acide est le plus souvent stimulée par les extraits de lactobacilles [10] n'ont pas de particularités concernant les enzymes étudiées dans ce travail, à l'exception de la souche 385 qui est la seule à ne pas être stimulée et à posséder des propriétés particulières (cf. plus haut). Par contre, la souche 445, qui possède à la fois une forte activité $\beta$-gal, une forte activité $P$ - $\beta$-gal et une très faible activité d'hydrolyse du lactose, présente un profil électrophorétique particulier des protéines solubles [9]. 


\section{Comparaison de S. thermophilus avec S. lactis et S. cremoris}

Jusqu'à présent, seule une souche de S. lactis, qui n'a d'ailleurs pas été isolée d'un produit laitier, posséderait à la fois une $\beta$-gal et une P- $\beta$-gal, ces deux enzymes ayant des activités spécifiques voisines [7], alors que $S$. lactis 7962, streptocoque lactique le mieux étudié, n'a qu'une activité P- $\beta$-gal négligeable [23].

Les $\beta$-gal et les P- $\beta$-gal de $S$. thermophilus ont des caractéristiques différentes de celles des enzymes correspondantes de $S$. lactis $[18,19$, $20]$ ou de $S$. cremoris $[13,23]$. Elles sont en particulier stables à $4^{\circ} \mathrm{C}$ et leurs activités diminuent en présence de sulfate d'ammonium $0,85 \mathrm{M}$, contrairement à celles de S. lactis 7962. D'autres données (Hemme et Nardi, en préparation) obtenues lors des étapes de purification confirment la remarquable stabilité de ces deux enzymes. Les enzymes des 10 souches de $S$. thermophilus conservent leur activité après électrophorèse à la différence de celles de S. lactis [20], bien que le poids moléculaire des enzymes de $S$. thermophilus, déterminé par filtration sur gel, soit voisin de 500000 , ce qui est proche du poids moléculaire du monomère de la $\beta$-gal de $S$. lactis 7962.

L'affinité pour l'ONPG est plus forte chez $S$. thermophilus que chez $S$. Lactis 7962 , et le pH optimal en tampon phosphate plus alcalin $(7,5$ à 7,7 contre 7,05$)$. Ce $\mathrm{pH}$ basique pourrait expliquer, au moins en partie, l'arrêt de l'acidification par $S$. thermophilus à un $\mathrm{pH}$ supérieur ( $\mathrm{pH}$ voisin de 5 ) à celui auquel peuvent acidifier d'autres streptocoques lactiques mésophiles $(\mathrm{pH} 4,5)$ et surtout les lactobacilles ( $\mathrm{pH} 4$, voire 3,5). Cela tendrait aussi à confirmer le bien-fondé de notre hypothèse [12] selon laquelle les souches capables de poursuivre la production d'acide lactique jusqu'à des valeurs basses de $\mathrm{pH}$ (en particulier $S$. thermophilus 385) sont celles qui maintiendraient le $\mathrm{pH}$ intracellulaire à une valeur favorable à l'action des enzymes glycolytiques. Le $\mathrm{pH}$ optimal trouvé pour l'enzyme purifiée [13] ou pour des cellules de $S$. cremoris traitées au toluène [23] était également plus bas ( $\mathrm{pH} 7)$.

Les températures optimales d'action de la $\beta$-gal et de la P- $\beta$-gal de $S$. lactis 7962 et de $S$. cremoris sont plus faibles que celles de $S$. thermophilus, ce qui va certainement de pair avec le caractère thermophile de cette dernière espèce. La résistance au chauffage des enzymes de la seule souche de $S$. cremoris étudiée [13] était voisine de la résistance moyenne des enzymes de nos 10 souches de $S$. thermophilus, bien que la variation observée dans notre étude incite à être prudent quand on extrapole à l'espèce entière les résultats obtenus avec une souche particulière. La B-gal de S. lactis 7962 est aussi thermolabile que celle de $S$. thermophilus 391, qui est particulièrement sensible au chauffage.

Le $\beta$-mercapto-éthanol stimule la $\beta$-gal et la P- $\beta$-gal de $S$. thermophilus. Cela a été observé chez $S$. lactis [20] et chez $S$. cremoris 
[13], ce qui indique certainement une stabilisation de formes multimériques [19]. Cette structure quaternaire des enzymes expliquerait l'effet activateur du galactose, du galactose-6-P et du glucose, effet difficilement explicable pour des enzymes monomériques. L'existence de sous-unités de poids moléculaire 47500 et 55500 détectées par électrophorèse en sodium-dodécyl sulfate (Hemme et Nardi, en préparation), valeurs proches de celle obtenue par Johnson et Mc Donald pour $S$. cremoris [13], renforce cette hypothèse.

Cette étude des $\beta$-gal et des P- $\beta$-gal de $S$. thermophilus confirme la particularité de cette espèce (voir la revue de Accolas et al. [3]). Mis à part les différences utilisées comme caractères taxonomiques habituels, l'équipement de $S$. thermophilus en aminopeptidase est très riche [3], expliquant diverses stimulations de la production d'acide $[1,5,10,11]$, et son métabolisme glucidique est différent de celui des streptocoques lactiques mésophiles et des lactobacilles [12, 35]. L'espèce apparaît cependant homogène [25], en dépit de quelques caractéristiques propres à certaines souches. Ces caractéristiques, par exemple l'hydrolyse efficace du lactose par la souche 391 ou le comportement très particulier de la souche 385 , pourraient avoir un intérêt en technologie.

Dans le cas de S. lactis, Farrow et Garvie [7] estimaient récemment que la présence concomitante de $\beta$-gal et de P- $\beta$-gal chez de "vraies " souches sauvages pourrait signifier que l'homme a sélectionné pour son usage des souches ayant seulement une activité P-B-gal. Cette supposition ne tient pas dans le cas de $S$. thermophilus qui, bien qu'utilisé depuis longtemps par l'homme dans la fabrication de fromages à pâte cuite et de divers laits fermentés, possède les deux activités $\beta$-gal et P-ß3-gal. L'usage de plus en plus fréquent, à l'heure actuelle, de $S$. thermophilus dans certaines fabrications fromagères (par exemple dans la fabrication des fromages à pâte molle) en remplacement des streptocoques lactiques mésophiles est à prendre en compte, dans le même ondre d'idées. Il ne serait donc pas nécessaire d'isoler de nouvelles souches "sauvages » ou «sauvages vraies » (sic) de biotopes très différents du lait et des produits laitiers. D'ailleurs, existe-t-il des sources autres que le lait, facilement accessibles, de streptocoques lactiques mésophiles ou thermophiles ? Rien n'est moins sûr dans l'état actuel des connaissances [30].

\section{Remerciements}

Nous tenons à remercier J. Auclair qui nous a engagé à développer l'étude de S. thermophilus, J.P. Accolas qui nous a fourni de judicieux conseils pour le choix et la culture des souches; Nicole Pamboukdjian et Elisabeth Hemme pour les traductions anglaise et allemande; Danièle Wahl, Michel Zygmunt pour leur aide lors de certains essais. 


\section{Ré s u m é}

Les $\beta$-galactosidases et phospho- $\beta$-galactosidases de 10 souches de Streptococcus thermophilus ont été étudiées en utilisant des extraits bruts solubles.

La température optimale de croissance des souches étudiées dans le milieu M 17 variait de 49 à $53^{\circ} \mathrm{C}$ selon les souches. Les souches se répartissaient en trois groupes selon les activités spécifiques $\beta$-gal et P- $\beta$-gal. Toutes les souches hydrolysaient l'ONPG et l'ONPG-6-P de façon semblable. Les activités d'hydrolyse du lactose étaient comparables pour 8 souches ; 1 souche était plus active et 1 très peu active. Les températures optimales d'action (ONPG) allaient de 49 à $53^{\circ} \mathrm{C}$, sans correspondre pour autant aux températures optimales de croissance sur le milieu M 17. Les $\mathrm{pH}$ optimaux se situaient entre 8 et 9 en tampon Tris- $\mathrm{HCl}$ et entre 7,3 et 7,8 en tampon phosphate pour la $\beta$-gal ; entre 7,7 et 8,1 d'une part et vers 7,6 (sauf 7,2 pour 1 souche) pour la $\mathrm{P}$ - $\beta$-gal. Les ions phosphate inhibaient la $\beta$-gal et non la P- $\beta$-gal. Pour chaque souche la $\beta$-gal et la P- $\beta$-gal avaient une thermorésistance comparable. Ces enzymes n'étaient pas stabilisées par le sulfate d'ammonium $(0,85 \mathrm{M})$; elles étaient stables à $4^{\circ} \mathrm{C}$ et étaient fortement activées par le $\beta$-mercapto-éthanol.

L'affinité de la $\beta$-gal pour l'ONPG variait légèrement selon les souches ( $\mathrm{K}_{\mathrm{s}}$ entre 0,15 et $0,38 \mathrm{mM}$ ). La $\beta$-gal était inhibée par un excès d'ONPG mais non par un excès de lactose, pour lequel elle avait une affinité plus faible $\left(\mathrm{K}_{\mathrm{M}}=22 \mathrm{mM}\right)$. Le lactose se comportait comme un inhibiteur compétitif vis-à-vis de la $\beta$-gal et de la P- $\beta$-gal. L'effet du galactose était généralement modéré mais parfois activateur. L'affinité de l'ONPG-6-P pour la P- $\beta$-gal était plus faible que celle de l'ONPG pour la $\beta$-gal $\left(\mathrm{K}_{\mathrm{M}}=6,6 \mathrm{mM}\right)$.

Ces résultats sont discutés. Ils confirment l'hypothèse de la présence chez $S$. thermophilus d'isoenzymes qui ont à la fois une affinité pour les $\beta$-galactosides (type $\beta$-gal) et pour les 6-phospho$\beta$-galactosides (type P- $\beta$-gal). Les propriétés de ces enzymes confirment par ailleurs l'hypothèse d'une structure oligomérique. Ces propriétés sont enfin différentes de celles des $\beta$-gal et des $\mathrm{P}$ - $\beta$-gal décrites pour les streptocoques mésophiles (S. lactis et S. cremoris).

\section{S u m m a ry}

\section{$\beta$-GALACTOSIDASES AND PHOSPHO- $\beta$-GALACTOSIDASES OF STREPTOCOCCUS THERMOPHILUS}

The $\beta$-galactosidases and phospho- $\beta$-galactosidases of 10 Streptococcus thermophilus strains have been studied by comparing some of their properties; measurements were performed using crude soluble extracts. 
Optimal growth temperature in M 17 medium varied from 49 to $53^{\circ} \mathrm{C}$ depending upon the strains. The strains can be divided into 3 groups according to the specific activities of $\beta$-gal and $P$ - $\beta$-gal. The ONPG and ONPG-6-P hydrolysis activities were always present, and equally strong for each strain. The hydrolysis activities of lactose were similar for 8 strains; one strain was particularly active and one not very active. The optimal active temperatures (ONPG) went from 49 to $53^{\circ} \mathrm{C}$ but were not related to the optimal growth temperature in M 17 medium. Optimal pH measurements were between 8 and 9 in Tris buffer and between 7,3 and 7,8 in Na-phosphate buffer. Phosphate ions inhibited the $\beta$-gal but not the $\mathrm{P}-\beta$-gal. The $\beta$-gal and $\mathrm{P}-\beta$-gal for a same strain were identically heat resistant, however that varied with the strains. These enzymes were stable at $4^{\circ} \mathrm{C}$ and were not stabilised by ammonium sulphate. The two activities were enhanced by $\beta$-mercaptoethanol.

The affinity of $\beta$-gal for ONPG varied slightly with the strains ( $K_{*}$ values were in between $0.15 \mathrm{mM}$ and $0.38 \mathrm{mM}$ ). An excess of ONPG but not of lactose inhibited the $\beta$-gal. The affinity for lactose was lower than that for ONPG $(22 \mathrm{mM})$. The lactose behaved like a competitive inhibitor in regand to ONPG and to ONPG-6-P. However the action of galactose on the hydrolysis kinetic was very moderate, sometimes activating. The P- $\beta$-gal affinity for ONPG-6-P was much lower than that of ONPG for $\beta$-gal $\left(K_{M}=6,6 \mathrm{mM}\right)$.

These results are discussed. They seem to confirm the previous hypothesis by which $S$. thermophilus strains possess at least two isoenzymes which have an affinity with $\beta$-galactosides ( $\beta$-gal type) at the same time with 6-phospho- $\beta$-galactosides (P- $\beta$-gal type). Their properties lead one to think of a possible oligomeric structure of the enzymes. Moreover their properties are different from those of $\beta$-gal and P- $\beta$-gal of the mesophilic lactic streptococci ( $S$. lactis and S. cremoris).

\section{Zusammenfassung}

\section{$\beta$-GALACTOSIDASEN UND PHOSPHO- $\beta$-GALACTOSIDASEN VON STREPTOCOCCUS THERMOPHILUS}

Unterbuckt wurden $\beta$-galactosiden und Phospho- $\beta$-galactosidasen von Streptococcus-thermophilus-Stämmen, indem einige ihrer auf löslichen Rohextrakten gemessenen Eigenschaften miteinander verglichen wurden. Die optimale Wachstumstemperatur im Milieu M 17 liegt zwischen 49 und $53^{\circ} \mathrm{C}$ je nach Stamm.

Die spezifischen $\beta$-gal und P-ß-gal Aktivitäten der 10 Stämme von S. thermophilus ermöglichen eine Aufteilung dieser Stämme in 3 Gruppen. Bei allen 10 Stämmen treten die Hydrolyseaktivitäten von ONPG und ONPG-6-P stets gemeinsam und in gleicher Stärke auf. 8 Stämme weisen ähnliche Laktose-Hydrolyseaktivitäten auf; ein 
Stamm ist besonders aktiv und einer sehr schwach. Die optimalen Aktivitätstemperaturen (ONPG) liegen zwischen 49 und $53^{\circ} \mathrm{C}$, ohne da $\beta$ dabei ein Zusammenhang mit den optimalen Wachstumstemperaturen im Milieu M 17 besteht. Die optimalen pH-Werte in Tris-HCl-Pufferlösung liegen zwischen 8 und 9, dagegen zwischen 7,3 und 7,8 in Na-Phosphat-Pufferlösung. Die Phosphationen inhibieren die $\beta$-gal, haben jedoch keine Wirkung auf die P- $\beta$-gal. Die $\beta$-gal und P- $\beta$-gal des gleichen Stammes haben dieselbe Resistenz bei Erhitzung, jedoch ist diese von Stamm zu Stamm verschieden. Diese Enzyme haben eine gute Resistenz bei $4^{\circ} \mathrm{C}$ und werden nicht durch Ammoniumsulfat stabilisiert, im Gegensatz zu $\beta$-gal der $S$. lactis 7962. Durch $\beta$-Mercaptoethanol entsteht eine starke Verstärkung beider Aktivitäten.

Die Affinität der $\beta$-gal für ONPG unterliegt leichten Schwankungen je nach Stamm ( $K_{m}$ zwischen $0,15 \mathrm{mM}$ und $0,38 \mathrm{mM}$ ). Die $\beta$-gal wird durch ein Uberma $\beta$ an ONPG inhibiert, jedoch nicht durch ein zu viel an Laktose. Die Affinität für Laktose ist schwächer als die für ONPG $\left(\mathrm{K}_{\mathrm{s}}=22 \mathrm{mM}\right)$. Die Laktose verhält sich als kompetitiver Inhibitor gegenüber ONPG und ONPG-6-P. Dagegen ist die Wirkung der Galaktose auf den Ablauf der Hydrolyse null oder aktivierend, was an eine oligomerische Struktur der Enzyme denken läßt - eine Hypothese, die durch das Verhalten bei der Elektrophorese und das Molekulargewicht verstärkt wird. Die Affinität der P-B-gal für ONPG6-P ist viel schwächer als die der ONPG für $\beta$-gal $\left(\mathrm{K}_{\mathrm{s}}=6,6 \mathrm{mM}\right)$.

Diese Ergebnisse bestätigen die Hypothese, aufgrund derer es bei $S$. thermophilus mindestens 2 Isoenzyme gibt, die gleichzeitig eine Affinität für die Galaktosiden (Typ $\beta$-gal) und für die 6-PhosphoGalaktosiden (Typ P- $\beta$-gal) haben. Andererseits sind ihre Eigenschaften sehr verschieden von denen der $\beta$-gal und P- $\beta$-gal, die man im Falle der mesophilen Milchstreptokokken erhält.

Reçu pour publication en juillet 1980.

\section{Bibliographie}

[1] Accolas (J. P.), Veaux (Monique) et Auclair (J.) (1971). - Etude des interactions entre diverses bactéries lactiques thermophiles et mésophiles, en relation avec la fabrication des fromages à pâte cuite. Le Lait, 51, 249-272.

[2] Accolas (J. P.), Bloquel (R.), Didienne (R.) et RÉGnieR (J.) (1977). - Propriétés acidifiantes des bactéries lactiques thermophiles en relation avec la fabrication du yoghourt. Le Lait, 57, 1-23.

[3] Accolas (J. P.), Hemme (D.), Desmazeaud (M. J.), Vassal (L.), Bouillanne (C.), et Veaux (Monique) (1980). - Les levains thermophiles. Propriétés et comportement en technologie laitière. Le Lait, 60, 487-524.

[4] Citti (J. E.), Sandine (W. E.) and Elliker (P. R.) (1965). - $\beta$-galactosidase of Streptococcus lactis. J. Bacteriol., 89, 937-942. 
[5] Desmazeaud (M.) et Devoyod (J. J.) (1970). - Action stimulante des microcoques caséolytiques sur les bactéries lactiques thermophiles. Mise en évidence de la nature peptidique des substances stimulantes. Ann. Biol. anim. Bioch. Biophys., 10, 413-430.

[6] ERICKSon (R. P.) and SteERs (E.) (1970). - Comparative study of isoenzyme formation of bacterial $\beta$-galactosidase. J. Bacteriol., 102, 79-84.

[7] FARRow (J.A. E.) and GARVIE (E. I,) (1979). - Strains of Streptococcus lactis which contain $\beta$-galactosidase. J. Dairy Res., 46, 121-125.

[8] Hall (B. G.) and Reeve (E. C.) (1977). - A third $\beta$-galactosidase in a strain of Klebsiella that possesses two lac genes. J. Bacteriol., 132, 219-223.

[9] Hemme (D.) et Nardi (M.) (1980). - Electrophorégrammes des protéines, de la $\beta$-galactosidase et de l'aldolase de Streptococcus thermophilus et des lactobacilles thermophiles. Le Lait, 60, 375-392.

[10] Hemme (D.), Schmal (V.) and Auclair (J.) (1981). - Effect of the addition of extracts of thermophilic lactobacilli on acid production by Streptococcus thermophilus in milk. J. Dairy Res., 48 (sous presse).

[11] Hemme (D.), VASsal (L.), Foyen (H.) et Auclair (J.) (1979). - Effet de l'addition de lactase au lait sur le développement des lactobacilles et des streptocoques thermophiles. Le Lait, 59, 597-614.

[12] Hemme (D.), WAHL (D.) et NARdi (M.) (1980). - Variations de l'équipement enzymatique de Streptococcus thermophilus. Le Lait, 60, 111-129.

[13] Johnson (K. G.) and Mc Donald (I. J.) (1974). - $\beta$-D-phosphogalactoside galactohydrolase from Streptococcus cremoris HP: purification and enzyme properties. $J$. Bacteriol., 117, 667-674.

[14] Jolly (R. C.) and Kosikowski (F. V.) (1976). - $\beta$-galactosidase activity by the enterococci. Milchwissenschaft, 31, 355-358.

[15] Lawrence (R. C.) and Thomas (T. D.) (1979). - The fermentation of milk by lactic acid bacteria. In Microbial technology: current state, future prospects, 29th Symposium of the Society for General Microbiology, A.T. Bull, D. C. Ellwood and C. Ratledge (Ed.), Cambridge University Press, Cambridge, 187-219.

[16] Leblanc (D. J.), Crow (V. L.), LeE (L. N.) and Garon (C. F.) (1979). Influence of the lactose plasmid on the metabolism of galactose by Streptococcus lactis. J. Bacteriol., 137, 878-884.

[17] Lineweaver (H.) and Burk (D.) (1934). - Determination of enzyme dissociation constants. J. Amer. Chem. Soc., 56, 658-666.

[18] Mc Feters.(G.A), Sandine (W.E.), Becker (R.R) and Elliker (P.R.) (1969). Some factors affecting association-dissociation of $\beta$-galactosidase from Streptococcus lactis 7962. Can. J. Microbiol., 15, 105-110.

[19] Mc Feters (G. A.), SAndine (W. E.) and Elliker (P. R.) (1967). - Purification and properties of Streptococcus lactis $\beta$-galactosidase. J. Bacteriol., 93, 914-919.

[20] Mc Feters (G. A.), Sandine (W. E.) and Elliker (P. R.) (1971). - Involvement of sulfhydryl groups in the $\beta$-galactosidase of Streptococcus lactis. J. Bacteriol., 108, 599-600.

[21] Mc Kay (L. L.), Miller (A.), Sandine (W. E.) and Elliker (P. R.) (1970). Mechanisms of lactose utilization by lactic acid streptococci: enzymatic and genetic analyses. J. Bacteriol., 102, 804-809.

[22] Mc Kay (L. L.), Walter (L. A.), Sandine (W. E.) and Elliker (P. R.) (1969). Involvement of phosphoenolpyruvate in lactose utilization by group $\mathrm{N}$ streptococci. J. Bacteriol., 99, 603-610. 
[23] Molskness (T. A.), Lee (D. R.), SAndine (W. E.) and Elliker (P. R.) (1973). $\beta$-D-phosphogalactoside galactohydrolase of lactic streptococci. Appt. Microbiol., 25, 373-380.

[24] OKaмото (T.) and Morichi (T.) (1979). - Distribution of $\beta$-galactosidase and $\beta$-phosphogalactosidase activity among lactic streptococci. Agric. Biol. Chem., 43, 2389-2390.

[25] Ottogalli (G.), Galli (A.) and Dellaglio (F.) (1979). - Taxonomic relationships between Streptococcus thermophilus and other streptococci. J. Dairy Res., 46, 127-131.

[26] Premi (L.), SAndine (W. E.) and Elliker (P. R.) (1972). - Lactose-hydrolysing enzymes of Lactobacillus species, Appl. Microbiol., 24, 51-57.

[27] Rao (M.V.R.) and DutTA (S. M.) (1977). - Production of $\beta$-galactosidase from Streptococcus thermophilus grown in whey. Appl. Environ. Microbiol., 34, 185-188.

[28] RaO (M. V. R.) and DutTA (S. M.) (1979). - An active $\beta$-galactosidase preparation from Streptococcus thermophilus. Indian J. Dairy Sci., 32, 187-188.

[29] Rossi (J.) et Trovarelli (G.) (1978). - Une enzyme active sur la liaison $\beta$-D-galactoside chez certaines levures lactose négatives du genre Hansenula H. et P. Sydow. XX $X^{\mathrm{e}}$ Congr. Int. Lait., E, 499-500.

[30] Sandine (W. E.), Radichi (P. C.) and Elliker (P. R.) (1972). - Ecology of the lactic streptococci. A review. J. Milk Food Technol., 35, 176-185.

[31] Somkuti (G. A.) and Steinberg (D. H.) (1979). - Adaptability of Streptococcus thermophilus to lactose, glucose and galactose. J. Food Protection, $42,885-887$.

[32] TeRzaghi (B.) and SANDINE (W. E.) (1975). - Improved medium for lactic streptococci and their bacteriophages. Appl. Microbiol., 27, 807-813.

[33] Thомаs (T. D.) (1976). - Regulation of lactose fermentation in group N streptococci. Appl. Environ. Microbiol., 32, 474-478.

[34] Thompson (J.) (1979). - Lactose metabolism in Streptococcus lactis: phosphorylation of galactose and glucose moities in vivo. J. Bacteriol., 140, 774-785.

[35] Thоmpson (J.) and Thomas (T. D.) (1977). - Phosphoenolpyruvate and 2phosphoglycerate: endogenous energy source(s) for sugar accumulation by starved cells of Streptococcus lactis. J. Bacteriol., 130, 583-595.

[36] Wallenfels (K.) and Molhotra (O. P.) (1961). - Galactosidases. In Advances in carbohydrate chemistry. Academic Press, New York City.

[37] Wierzbicki (L. E.) and Kosikowski (F. V.) (1973), - Lactase potential of various microorganisms grown in whey. J. Dairy Sci., 56, 26-32.

[38] Wierzbicki (L. E.) and Kosikowski (F. V.) (1973). - Kinetics of lactose hydrolysis in acid whey by $\beta$-galactosidase from Aspergillus niger. J. Dairy Sci., 56, 1396-1399. 